\title{
Communication of a mental health diagnosis: a systematic synthesis and narrative review
}

\author{
Alyssa C. Milton*1 2\& Barbara A. Mullan ${ }^{13}$ \\ ${ }^{1}$ School of Psychology University of Sydney Australia \\ 2 Division of Psychiatry (Formerly Mental Health Sciences) University College London UK \\ ${ }^{3}$ School of Psychology and Speech Pathology, Curtin University, Australia \\ *Corresponding author: Alyssa Milton School of Psychology University of Sydney NSW 2006 \\ Australia (email: amil2403@uni.sydney.edu.au)
}

Conflicts of interest: None 
Background: There is limited understanding of the mechanisms used to effectively communicate with service-users about their mental health diagnoses. Aims: To conduct a systematic synthesis of studies that present data on the communication of a psychiatric diagnosis. Methods: Comprehensive database and manual searches were conducted resulting in the inclusion of thirty quantitative and qualitative papers. Results: The majority of studies were descriptive. The rate of service-users being informed of their diagnosis has increased over the last decade. Consumer communication preferences were not always satisfactorily addressed in practice. Individual characteristics of service-users and clinicians influenced whether a diagnostic discussion took place. Results from intervention studies aimed at facilitating diagnostic communication reported significant improvements in service-user satisfaction and mood, and clinician communication skills. Conclusions: This review highlights a gap in the system of communication between clinicians and services-users. To assist clinicians to talk effectively with individuals about their mental health, communication protocols and training need to be further developed and assessed. Such developments would benefit from well-designed randomised controlled trial protocols, should incorporate serviceusers’ preferences and address stigma related concerns. Declarations of Interest: none

\section{Key Words:}

Mental health; Diagnosis; Communication models; breaking bad news 


\section{Introduction}

At an individual level, a mental health diagnosis (MHD) can have an impact on a person's lifestyle, future choices and level of hope (Cleary et al.,2010a). From a macro perspective, the annual incidence of MHD remains high; UK rates for a depression diagnosis are fourteen per every thousand (Rait et al.,2009), and thirty two per hundred thousand for bipolar and psychotic related disorders (Kirkbride et al.,2012). Despite this high incidence and impact, there remains a limited understanding of how best to communicate diagnostic news (Cleary et al.,2009).

The DSM-V has prompted widespread discussion concerning the concepts, constructs and validity of MHD (Gornall,2013; Torjesen,2013; Wykes \& Callard,2010). In practice, conflicting beliefs can make the subject of diagnosis challenging and ambiguous for clinicians and service-users. A clearer understanding of the information needs of service-users and strategies that may assist clinicians to communicate about MHD could prove practically useful. To assist clinicians to discuss diagnostic news effectively, oncology specialists have developed comprehensive guidelines (Clayton et al.,2007; Girgis \& Sanson-Fisher,1995) and protocols (Baile et al.,2000; Rabow \& McPhee,1999). In the mental health field, the specific treatment guidelines and recommendations (APA,2008; NICE,2002, 2006, 2009; RANZCP,2005) do not explicitly suggest that practitioners hold responsibility to disclose diagnoses nor do they outline how best to communicate such news (Hwang,2008).

There have been at least five papers providing viewpoints summarising the mechanisms involved in communicating MHD. All have been narrative literature reviews (Atkinson,1989; Cleary, et al.,2009; Lequesne \& Hersh,2004; Mitchell,2007; Rose \& Thornicroft,2010) that lacked systematic synthesis. Additionally, some focused on communication of news for subtypes of mental health issues (Atkinson,1989; Lequesne \& Hersh,2004) or concentrated chiefly on making comparisons with the oncology field (Mitchell,2007). Given this growing evidence base, a systematic synthesis of literature, which includes a broad spectrum of MHD, has been called for in the literature (Cleary, et al.,2009).

\subsection{Aims}

We aimed to review the published literature to address six primary research questions: 
i. What are the rates of receiving and providing a MHD;

ii. What is the impact of a diagnosis on individuals;

iii. What are factors influencing a diagnostic discussion taking place;

iv. What are the preferences and satisfaction levels of service-users when receiving diagnostic news;

v. What are the outcomes from interventions designed to improve communication relating to diagnosis; and

vi. What are the current recommendations for effectively communicating MHD?

2. Methods

\subsection{Types of studies}

A protocol for study inclusion and extraction was defined and evaluated by the authors. Both quantitative and qualitative data describing the provision or receipt of a MHD were considered. Commentaries, opinions, single casestudies, literature reviews and scale development were excluded.

\subsection{Types of Participants}

Included studies:

i. $\quad$ Presented data from either clinician and/or service-user samples;

ii. Included service-users aged 12 years and older; and

iii. Included MHD that met the following ICD-10 criteria (F20-F29: schizophrenia, schizotypal and delusional disorders; F30-F39: Mood [affective] disorders; F40-F48: Neurotic, stress-related and somatoform disorders, (WHO,1992) or the DSM-IV equivalent (APA,2000). Samples with mixed diagnoses were included.

\subsection{Types of outcome measures}

Outcomes reported in intervention studies were analysed post-intervention and at any further time points if applicable. Outcomes from descriptive and qualitative studies were used to add depth to the findings. Outcomes of interest included:

- $\quad$ Service-user focused outcomes (e.g. satisfaction, preferences, clinical change) 
- Clinician focused outcomes (e.g. skills)

- Rates of diagnostic discussion

\subsection{Literature search strategy}

A systematic database search was conducted. PsycINFO, Medline and CINAHL were searched to locate studies published in English (1983 to September Week 1 2012) using the search terms: communicat* OR "breaking news" OR tell* OR disclosure, AND “mental disorders”* OR psychiatric OR “mental health”, AND diagnos*. Google Scholar, GreyLit and Zetoc were searched and references were hand-screened. Abstracts were screened using the review protocol by the first author. Studies meeting full text inclusion criteria were reviewed by both authors to establish final review admittance. Inter-rater agreement was substantial $(\kappa=0.98)$. Discussion took place until consensus was reached.

\subsection{Data Extraction, management and analysis}

The first author extracted data which were reviewed by the second. Participant, intervention characteristics and outcomes for all available data were extracted. Data were reported as means, standard deviations, percentages and pvalues as presented in original papers. No additional statistical analysis was performed due to lack of sufficient RCTs.

2.6 Evaluation of study evidence

An adapted quantitative evidence rating system (NHMRC,1999, 2000) was used. The level assigned reflects the degree to which bias has been eliminated by study design; with lower levels (e.g. L-I) corresponding with lower bias and higher quality methodology. This framework includes: (1) L-I: systematic reviews of randomized controlled trials (RCT); (2) L-II: RCTs; (3) L-III-1: pseudo-RCTs; (4) L-III-2: comparative studies with non-randomized concurrent controls, case-control studies or interrupted time series with control group; (4) L-III-3: comparative studies with historical control, two or more single-arm studies, or interrupted time series without parallel control; (5) L-IV-1: case series, either post-test or pre-test/post-test; and (6) L-IV-2: descriptive studies. Those meeting L-II criteria were further assessed using the Cochrane Collaboration Risk of Bias Tool (Higgins et 
al.,2011). Both authors independently rated for biases for: sequence generation; allocation concealment; blinding; selective outcome reporting; incomplete data; and other biases. Differences were resolved through discussion.

Qualitative studies are beneficial to systematic reviews (The Campbell Collaboration,2001), but rigor needs to be established (NHMRC,2006). Therefore a qualitative evaluation tool (NHMRC,2006) assessed such studies for (1) quality of aims, methodology, sampling strategy, and analysis; (2) evidence strength (range: 1 very low to 4 very high) and; (3) evidence relevance (range: 1 not applicable to 4 very applicable). Both authors independently rated each qualitative study using the criteria for each item. Differences were resolved through discussion.

\section{Results}

\subsection{Literature search results}

A total of 1851 records were obtained with fifteen identified through hand screening. Thirty studies met criteria for review after duplicate removal and screening (See Figure 1 for study flow).

\section{[INSERT-FIGURE-1-ABOUT-HERE]}

\subsection{Evidence strength and study quality}

\subsubsection{Quantitative research (23 studies: Table 1)}

Included papers are presented in Table 1. Most studies were descriptive (Level IV-2), thus weaker evidence strength should be considered when interpreting results. The risk of bias rating (Higgins, et al.,2011) is presented in Figure 2 for the RCT studies (Gerrity et al.,1999; Wong et al.,2007). Sequence generation was not sufficiently described in both trials. Risk of bias for concealment of the allocation sequence was low (Gerrity, et al.,1999) or unclear (Wong, et al.,2007). For both studies, blinding of assessors and participants created a low risk of bias, as did missing data (i.e. attrition bias). As neither RCT study registered their trial protocol, bias for selective outcome reporting was unclear.

[INSERT-TABLE-1-(LANDSCAPE)-AND-FIGURE-2-ABOUT-HERE] 


\subsubsection{Qualitative research (7 studies: Table 1)}

Qualitative studies scored moderately to highly on the evaluation tool for quality and relevance, whilst study strength varied. Grounded theory studies lacked sufficient detail regarding checking methods to establish rigor (Buston,2002; Gallagher et al.,2010; Hwang,2008), and sample data to comfortably reach saturation (Gallagher, et al.,2010; Hwang,2008) as per recommendations on achieving maximum variation in data (Kuzel,1992).

\subsection{Rates of diagnostic discussion}

Rates of service-users receiving or having knowledge of their diagnosis were collected in nine (L-IV) studies (Cleary, et al.,2010a; Ganesan et al.,2011; Luderer \& Bocker,1993; Magliano et al.,2008; Marzanski et al.,2002; Seedat et al.,2002; Shergill et al.,1998; Thornicroft et al.,2009; Trump \& Hugo,2006). Studies conducted prior to the last decade, reported low rates of diagnostic discussion for both schizophrenia diagnoses and general MHD (30\%65\%). In contrast, studies conducted in the past ten years reported higher rates of diagnostic discussion for both groups (77\%-88\%), with the exception of service-users who had immigrated (22\%). Incorrect diagnoses were reported as occurring in three L-IV studies (Mead et al.,1997; Seedat, et al.,2002; Trump \& Hugo,2006). This delayed help-seeking, required multiple doctors' involvement and typically took one to two years to receive a correct diagnosis (Seedat, et al.,2002; Trump \& Hugo,2006).

\subsection{Impact of a diagnosis}

After receiving a diagnosis, individuals experienced a range of different reactions; including relief, viewing the diagnosis as validating or helpful to treatment, experiencing uncertainty, or rejecting the diagnosis as it pathologised issues or did not help individuals make sense of their situation (Buston,2002; Gallagher, et al.,2010; Lewis,1995; Wisdom \& Green,2004). Two studies reported that clinicians not diagnosing resulted in the individual experiencing a sense of doubt regarding the validity of the challenges they faced (Lewis,1995) or feelings of distress due to the perception that they were not believed (Buston,2002). Poor communication at the time of diagnosis was confusing, as were multiple diagnoses (Gallagher, et al.,2010). Although many service-users did not believe excessive stigma was associated with receiving psychiatric treatment (Greenwood et al.,2000), anxiety about stigma was reported as a reaction to diagnostic news (Gallagher, et al.,2010). Due to stigma related concerns, individuals felt the diagnosis could impact on their social identity (Lewis,1995), their relationships with others (Magliano, et al.,2008; 
Thornicroft, et al.,2009) and their willingness to share diagnostic information with others (Gallagher, et al.,2010). Furthermore it may cause strong sense of shame due to their cultural beliefs (Hwang,2008) or could lead to drop out from treatment (Seedat, et al.,2002). It was reported that individuals who held hope for future recovery had a less pronounced perception of affective and social difficulties as a result of a schizophrenia diagnosis (Magliano, et al.,2008).

\subsection{Factors influencing diagnostic discussion}

Factors that influenced diagnostic discussions taking place were reported in eight studies (L-IV evidence). The most frequently reported factor that influenced disclosure was the type of diagnosis (Clafferty et al.,2001; Cleary, et al.,2010a; Cleary et al.,2010b; Gantt \& Green,1985; Green \& Gantt,1987; McDonald-Scott et al.,1992; Shergill, et al.,1998). Schizophrenia was less frequently disclosed in service-user surveys (Luderer \& Bocker,1993); with 45\% not receiving any information compared to an average of $20 \%$ for other diagnoses. This was also the case in psychiatrist surveys (Clafferty, et al.,2001; Gantt \& Green,1985; Green \& Gantt,1987; Luderer \& Bocker,1993; McDonald-Scott, et al.,1992; Shergill, et al.,1998), except when episodes were recurrent (Clafferty, et al.,2001). In these studies, a full schizophrenia diagnosis was disclosed at a lower rate (7 - 59\%) when compared with other diagnoses such as depression (71-98\%), bipolar disorder (61-96\%) or anxiety related disorders (58-96\%). Providing a substitute diagnosis in place of a schizophrenia diagnosis was reported as common practice (Clafferty, et al.,2001; Cleary, et al.,2010b; Luderer \& Bocker,1993; McDonald-Scott, et al.,1992). Using a substitute term for schizophrenia was more frequent ( $53 \%$ of cases) compared to other diagnoses ( $13 \%$ on average; Luderer \& Bocker, 1993). This remained the case even when exact diagnostic information was sought by service-users (McDonaldScott, et al.,1992). Clinicians using substitute diagnoses was associated with service-users experiencing a poorer understanding of their condition (Luderer \& Bocker,1993). The most frequent substitute for schizophrenia was psychosis, psychotic illness and major mental illness (Clafferty, et al.,2001). Stigma was reported as a reason why psychiatrists might not disclose diagnosis (Green \& Gantt,1987; Hwang,2008; McDonald-Scott, et al.,1992). Health professionals felt that the information must be handled with extreme care and support (Clafferty, et al.,2001) such as discussing fears and concerns (Cleary, et al.,2010b) and actively reducing stigma (Levin et al.,2011). 
Service-user characteristics influenced diagnostic discussion; including their likelihood of becoming distressed, insight, understanding of the diagnostic consequences (Cleary, et al.,2010a; Cleary, et al.,2010b), desire for information (McDonald-Scott, et al.,1992; Shergill, et al.,1998) and agreement between service-users and clinicians concerning the need for medication (Cleary, et al.,2010a; Cleary, et al.,2010b). Clinician characteristics influencing diagnostic discussion included the clinician’s professional background (Gantt \& Green,1985; Trump \& Hugo,2006), their age, and time since qualification (Clafferty, et al.,2001; McDonald-Scott, et al.,1992). Clinicians who were psychiatrists, younger and newer to the profession reported more frequent diagnostic disclosure. External factors impacting on diagnosis included insurance and funding for treatment (Mead, et al.,1997).

\subsection{Service-user preferences and satisfaction}

Across studies, the majority of service-users (62\% - 88\%) wanted diagnostic information (Cleary, et al.,2010a; Jha et al.,2001; Magliano, et al.,2008; Marzanski, et al.,2002; Shergill, et al.,1998) and indicated that they felt they had a right to access diagnostic information (Clafferty, et al.,2001; Cleary, et al.,2010a; Luderer \& Bocker,1993;

Magliano, et al.,2008; Shergill, et al.,1998) . Six studies recommended that services should account for service-user preferences and needs when discussing MHD (Clafferty, et al.,2001; Cleary, et al.,2010a; Luderer \& Bocker,1993; Magliano, et al.,2008; Marzanski, et al.,2002; Shergill, et al.,1998). Preference for information varied across psychiatric settings. Hospital based service-users did not want diagnostic information in $28 \%$ of cases when in an acute ward setting (Marzanski, et al.,2002) and 10-12\% in general in-patient settings (Cleary, et al.,2010a; Shergill, et al.,1998). Only 0-5\% did not desire information when accessing community based support (Magliano, et al.,2008; Shergill, et al.,1998).

A total of thirty-two separate items from five studies (L-IV evidence), have been included in surveys to describe and assess service-users' preferences and satisfaction towards MHD communication. Table 2 presents items that either aid facilitation of a diagnostic discussion or outline conversation content. The majority of evidence for preferences and satisfaction is extracted from one study (Cleary, et al.,2010a). Service-users reported lower satisfaction with the delivery of diagnostic communication items such as information on the specific illness, medication side effects and treatment options than the level of importance they attached to the item. Qualitative studies supported this finding as 
a gap between service-users information preferences and satisfaction was reported (Buston,2002; Greenwood, et al.,2000; Lewis,1995).

\section{[INSERT-TABLE-2-ABOUT-HERE]}

\subsection{Outcomes from interventions}

Data reporting service-user and clinician outcomes from six intervention studies are presented in Table 3 . Two studies achieved L-II evidence with low risk of bias (Gerrity, et al.,1999; Wong, et al.,2007), three received L-III evidence (Eisenthal et al.,1983; Holm-Denoma et al.,2008; Scardovi et al.,2003) and one was categorized as a L-IV study (McNeilly \& Wengel,2001). For service-user outcomes, diagnostic feedback had positive effects on mood, with no evidence of negative impacts (Holm-Denoma, et al.,2008). Six of nine diagnostic communication strategies were significantly correlated with service-user satisfaction (Eisenthal, et al.,1983). For clinician related outcomes, training resulted in significant improvements in GPs’ communication skills (Gerrity, et al.,1999; Scardovi, et al.,2003; Wong, et al.,2007), and medical students’ knowledge and attitudes (McNeilly \& Wengel,2001) across fourteen items. The remaining items did not result in significant improvements. No studies reported any negative impacts for clinician or service-user outcomes.

\section{[INSERT-TABLE-3-ABOUT-HERE]}

\subsection{Protocols for MHD communication}

Development of protocols was recommended in six studies (Clafferty, et al.,2001; Cleary, et al.,2010a; Cleary, et al.,2010b; Hwang,2008; Levin, et al.,2011; McNeilly \& Wengel,2001) and are presented in table 4. The SPIKES protocol was most frequently utilized as a communication tool in the development of questionnaires (Cleary, et al.,2010a; Cleary, et al.,2010b) and training (McNeilly \& Wengel,2001). This is a framework borrowed from oncology where it was developed to synthesize information in a stepwise fashion (See Table 4; (Baile, et al.,2000)) and has been found to be effective, even after extensive clinical research (Cleary, et al.,2009). The six SPIKES

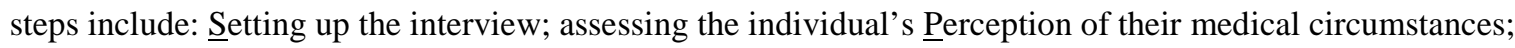


obtaining their Invitation to receive the information; giving the requisite Knowledge; responding Empathically to emotions; and Summarizing the treatment processes. Additionally, Levin and colleagues (2011) presented a model for communicating news specifically related to schizophrenia, and Hwang (2008) presented guidelines that address cultural issues when delivering diagnostic information. No protocols have been assessed in terms of their clinical effectiveness in the mental health field.

\section{[INSERT-TABLE-4-ABOUT-HERE]}

\section{Discussion}

\subsection{Summary of findings}

Globally over the last thirty years, there is evidence of a shift towards more open disclosure of MHD. Schizophrenia, remains less openly discussed. This review found that there is scope for service improvements, as a gap between the information preferences of service-users and their level of satisfaction with diagnostic discussion was present in both quantitative and qualitative studies. Mental health facilities should account for service-user preferences and needs when discussing MHD, which may vary across psychiatric settings and across cultures. Although the evidence is currently limited, intervention studies reported significant benefits to information giving with no evidence of negative outcomes (L-II and L-III evidence). Negative impacts, such as stigma associated with diagnosis, were reported by some service-users in qualitative and descriptive studies (L-IV).

Development of detailed protocols for communicating a MHD has been recommended to address communication gaps and facilitate a supportive discussion. Such communication models may feed into clinician or student training. Although communication interventions have improved elements of clinician communication the evidence remains incomplete. This is attributable to current limited evidence from RCT protocols, reliance on small samples and a lack of assessment of service-user outcomes. Furthermore, data have been gathered for intervention studies from a narrow range of professional groups (GPs and medical students only) which limits the generalisability of intervention results.

\subsection{Comparisons with other reviews}


These findings are supported in previous narrative discussion papers. Overall, individuals maintain an overall right to information (Atkinson,1989; Cleary, et al.,2009). However a communication gap exists, as clinicians underestimate the desires of service-users to access information about their own condition (Rose \& Thornicroft,2010). Some suggested benefits to open diagnostic communication include increased service-user autonomy and collaboration (Lequesne \& Hersh,2004), improved access to information concerning features, associations and treatment, and an increased sense of efficacy towards self-management (Lequesne \& Hersh,2004; Rose \& Thornicroft,2010). An attempt to address stigma is also essential (Rose \& Thornicroft,2010). To date, outcomes of positive diagnostic interactions have not been fully assessed and systematic research into delivering MHD is required (Cleary, et al.,2009). Reviews have suggest that the SPIKES protocol may be of practical use when guiding such ventures (Cleary, et al.,2009; Seeman,2010) which now may be expanded to include other models.

\subsection{Limitations}

The majority of reviewed studies were descriptive, resulting in weaker evidence. This limitation was expected due to the exploratory nature of the research aims, which is a issue also found in diagnostic communication reviews for oncology (Fujimori \& Uchitomi,2009). Furthermore, as this is an under researched area, there are few studies reporting data that address this review's specific research questions. This may ultimately bias results towards these studies findings. Despite these issues, the research can still be viewed as integral to understanding the factors associated with communicating MHD and developing pathways for future research.

\subsection{Implications for Research}

Despite the complexities in undertaking RCT research compared to gathering descriptive data, this is an essential next step. There is particular scope for clinician training, with qualitative research remaining a useful adjunct that provides greater depth of understanding to the diagnostic experience. Development of communication protocols may be a useful guide to training, but there are current existing limitations. Firstly, the SPIKES protocol has been borrowed from oncology. At face value the protocol fits within a mental health context (see Table 4); however, more rigorous evaluation of its suitability in psychiatric settings is essential. For example, themes raised in qualitative and descriptive studies, such as stigma, are not directly addressed. Actively addressing stigma stress associated with diagnosis may be crucial to future psycho-educational study designs, particularly as individuals who hold hope for 
future recovery reported fewer perceived social difficulties due to diagnosis (Magliano, et al.,2008). The model offered by Levin and colleagues (2011) is specifically tailored to discussing schizophrenia diagnoses and addresses stigma. Its application to other MHD should be explored. Furthermore, this model was developed through gauging the views of psychiatry alumni. It is possible that practitioners of other clinical disciplines, service-users and carers may offer unique and valuable perspectives. Broadening the consultation process, as was done in the development of oncology-related consensus guidelines (Clayton, et al.,2007), is recommended. Furthermore, further research is needed to understand whether the fundamental principles of communication should remain the same across various mental health contexts, particularly as information preferences varied across psychiatric settings and across cultures.

\subsection{Implications for practice}

Communication protocols may provide a foundation for clinician training. The current evidence for the efficacy of training shows promise, but is limited in terms of quality and quantity. Providing training to improve clinician competencies was viewed as a priority (Cleary, et al.,2010b; Gerrity, et al.,1999; Jha, et al.,2001; Luderer \& Bocker,1993; Scardovi, et al.,2003; Shergill, et al.,1998; Wong, et al.,2007), and surveyed clinicians indicated a need and willingness to undertake training (Cleary, et al.,2010b). A future educational agenda should be developed and evaluated both systematically and rigorously considering the current research and limitations.

\subsection{Conclusions}

Given growing awareness and high incidence of mental health conditions in the community, there is a need to understand how best to initiate a conversation with individuals about their mental health, and where necessary, to communicate a diagnosis. Communication protocols are presented in the literature, but there is yet to be an empirically tested overarching model informing training specific to mental health. Overall, the literature presented calls for an open dialogue that discusses information in a clear, person-centred, collaborative manner that incorporates service-users’ preferences, individuals’ rights and addresses stigma related concerns. These underlying principals may pave the way for future well-designed clinician training and protocol development that supports the individual whilst accounting for the complexities inherent in the mental health field. 
References

APA. (2000). Diagnostic and statistical manual of mental disorders (4th ed., text rev. ed.). Washington, DC: Author.

APA. (2008). Principles of Medical Ethics With Annotations Especially Applicable to Psychiatry. Retrieved from http://www.fpamed.com/files/principles-of-medical-ethics-with-annotationsespecially-applicable-to-psychiatry.pdf

Atkinson, J. (1989). To tell or not to tell the diagnosis of schizophrenia. J Med Ethics, 15(1), 21-24.

Baile, W., Buckman, R., Lenzi, R., Glober, G., Beale, E., \& Kudelka, A. (2000). SPIKES-A six-step protocol for delivering bad news: Application to the patient with cancer. Oncologist, 5(4), 302311.

Buston, K. (2002). Adolescents with mental health problems: What do they say about health services? $J$ Adolescence, 25(2), 231-242.

Clafferty, R., McCabe, E., \& Brown, K. (2001). Conspiracy of silence? Telling patients with schizophrenia their diagnosis. Psychiatr Bull, 25(9), 336-339.

Clayton, J., Hancock, M., Butow, P., Tattersall, M., Currow, D., Mitchell, G., et al. (2007). Clinical practice guidelines for communicating prognosis and end-of-life issues with adults in the advanced stages of a life-limiting illness, and their caregivers: Australasian Medical Publishing.

Cleary, M., Hunt, G., Escott, P., \& Walter, G. (2010a). Receiving difficult news: Views of patients in an inpatient setting. J Psychosoc Nurs Ment Health Serv, 48(6), 40-48.

Cleary, M., Hunt, G., \& Horsfall, J. (2009). Delivering Difficult News in Psychiatric Settings. Harvard Review of Psychiatry, 17(5), 315-321.

Cleary, M., Hunt, G., \& Walter, G. (2010b). Delivering difficult news. Views of mental health staff in inpatient settings. J Psychosoc Nurs Ment Health Serv, 48(6), 32-39.

Eisenthal, S., Koopman, C., \& Lazare, A. (1983). Process analysis of two dimensions of the negotiated approach in relation to satisfaction in the initial interview. J Nerv Ment Dis, 17(1), 49-54.

Fujimori, M., \& Uchitomi, Y. (2009). Preferences of cancer patients regarding communication of bad news: A systematic literature review. Jpn J Clin Oncol, 39(4), 201-216.

Gallagher, A., Arber, A., Chaplin, R., \& Quirk, A. (2010). Service users' experience of receiving bad news about their mental health. J Ment Health, 19(1), 34-42.

Ganesan, S., Mok, H., \& McKenna, M. (2011). Perception of mental illness: preliminary exploratory research at a cross-cultural outpatient psychiatric clinic. Int J Soc Psychiatr, 57(1), 81-89.

Gantt, A., \& Green, R. (1985). Telling the diagnosis: Implications for social work practice. Soc Work Health Care, 11(2), 1985-1986.

Gerrity, M., Cole, S., Dietrich, A., \& Barrett, J. (1999). Improving the recognition and management of depression: Is there a role for physician education? J Fam Pract, 48(12), 949-957.

Girgis, A., \& Sanson-Fisher, R. (1995). Breaking bad news: consensus guidelines for medical practitioners. J Clin Oncol, 13(9), 2449-2456.

Gornall, J. (2013). DSM-5: a fatal diagnosis? BMJ, 346.

Green, R., \& Gantt, A. (1987). Telling patients and families the psychiatric diagnosis: A survey of psychiatrists. Hosp Community Psych, 38(6), 666-668.

Greenwood, N., Hussain, F., Burns, T., \& Raphael, F. (2000). Asian in-patient and carer views of mental health care. Asian views of mental health care. J Ment Health, 9(4), 397-408.

Higgins, J. P., Altman, D. G., Gøtzsche, P. C., Jüni, P., Moher, D., Oxman, A. D., et al. (2011). The Cochrane Collaboration's tool for assessing risk of bias in randomised trials. BMJ: British Medical Journal, 343.

Holm-Denoma, J., Gordon, K., Donohue, K., Waesche, M., Castro, Y., Brown, J., et al. (2008). Patients' affective reactions to receiving diagnostic feedback. [doi: 10.1521/jscp.2008.27.6.555]. J Soc Clin Psychol, 27(6), 555-575. 
Hwang, W. (2008). Diagnostic nondisclosure of schizophrenia to Chinese American patients. Asian J Couns, 15(1), 1-31.

Jha, A., Tabet, N., \& Orrell, M. (2001). To tell or not to tell: Comparison of older patients' reaction to their diagnosis of dementia and depression. Int J Geriatr Psych, 16(9), 879-885.

Kirkbride, J. B., Errazuriz, A., Croudace, T. J., Morgan, C., Jackson, D., Boydell, J., et al. (2012). Incidence of schizophrenia and other psychoses in England, 1950-2009: a systematic review and meta-analyses. PLoS ONE, 7(3), e31660.

Kuzel, A. (1992). Sampling in qualitative inquiry. In B. Crabtree \& W. Miller (Eds.), Doing qualitative research (pp. 31-44). Newbury Park, CA: Sage.

Lequesne, E., \& Hersh, R. (2004). Disclosure of a diagnosis of borderline personality disorder. $J$ Psychiatr Pract, 10(3), 170-176.

Levin, T., Kelly, B., Cohen, M., Vamos, M., Landa, Y., \& Bylund, C. (2011). Using a psychiatry e-list to develop a model for discussing a schizophrenia diagnosis. Psychiat Serv, 62(3), 244-246.

Lewis, S. (1995). A search for meaning: Making sense of depression. J Ment Health, 4(4), 369-382.

Luderer, H., \& Bocker, F. (1993). Clinicians' information habits, patients' knowledge of diagnoses and etiological concepts in four different clinical samples. Acta Psychiat Scand, 88(4), 266-272.

Magliano, L., Fiorillo, A., Malangone, C., Del Vecchio, H., \& Maj, M. (2008). Views of persons with schizophrenia on their own disorder: An Italian participatory study. Psychiatr Serv, 59(7), 795799.

Marzanski, M., Jainer, A., \& Avery, C. (2002). What have you been told about your illness? Information about diagnosis among psychiatric inpatients. Int J Psychiatry Clin Pract, 6, 103-106.

McDonald-Scott, P., Machizawa, S., \& Satoh, H. (1992). Diagnostic disclosure: A tale in two cultures. Psychol Med, 22(1), 147-157.

McNeilly, D., \& Wengel, S. (2001). The "ER" seminar: Teaching psychotherapeutic techniques to medical students. Acad Psychiatr, 25(4), 193-200.

Mead, M., Hohenshil, T., \& Singh, K. (1997). How the DSM system is used by clinical counselors: A national study. J Ment Health Couns, 19(4), 383-401.

Mitchell, A. (2007). Reluctance to disclose difficult diagnoses: A narrative review comparing communication by psychiatrists and oncologists. Support Care Cancer, 15(7), 819-828.

NHMRC. (1999). A guide to the development, implementation and evaluation of clinical practice guidelines. Canberra: NHMRC.

NHMRC. (2000). Psychosocial clinical practice guidelines: Information, support and counseling for women with breast cancer. Canberra: NHMRC.

NHMRC. (2006). Guidelines for a palliative approach to residential aged care: A systematic review of the literature. Canberra: NHMRC.

NICE. (2002). Schizophrenia: core interventions in the treatment and management of schizophrenia in primary and secondary care. London: NICE.

NICE. (2006). Bipolar disorder. The management of bipolar disorder in adults, children and adolescents, in primary and secondary care guidance type: clinical guideline. London: NICE.

NICE. (2009). Depression in adults: The treatment and management of depression in adults London: NICE.

Rabow, M., \& McPhee, S. (1999). Beyond breaking bad news: how to help patients who suffer. West $J$ Med, 171(4), 260-263.

Rait, G., Walters, K., Griffin, M., Buszewicz, M., Petersen, I., \& Nazareth, I. (2009). Recent trends in the incidence of recorded depression in primary care. The British Journal of Psychiatry, 195(6), 520524.

RANZCP. (2005). Royal Australian and New Zealand College of Psychiatrists clinical practice guidelines for the treatment of schizophrenia and related disorders. Australian and New Zealand Journal of Psychiatry, 39(1-2), 1-30. 
Rose, D., \& Thornicroft, G. (2010). Service user perspectives on the impact of a mental illness diagnosis. Epidemiol Psichiatr Soc, 19(2), 140-147.

Scardovi, A., Rucci, P., Gask, L., Berardi, D., Leggieri, G., Ceroni, G., et al. (2003). Improving psychiatric interview skills of established GPs: Evaluation of a group training course in Italy. Fam Pract, 20(4), 363-369.

Seedat, S., Stein, D., Berk, M., \& Wilson, Z. (2002). Barriers to treatment among members of a mental health advocacy group in South Africa. Soc Psych Psych Epid, 37(10), 483-487.

Seeman, M. (2010). Breaking Bad News: Schizophrenia. [Article]. Journal of Psychiatric Practice, 16(4), 269-276.

Shergill, S., Barker, D., \& Greenberg, M. (1998). Communication of psychiatric diagnosis. Social Psychiatry \& Psychiatric Epidemiology, 33(1), 32-38.

The Campbell Collaboration. (2001). Guidelines for the preparation of review protocols. Retrieved from the Campbell Collaboration web site on May, 15, 2006.

Thornicroft, G., Brohan, E., Rose, D., Sartorius, N., \& Leese, M. (2009). Global pattern of experienced and anticipated discrimination against people with schizophrenia: A cross-sectional survey. [doi: 10.1016/S0140-6736(08)61817-6]. Lancet, 373(9661), 408-415.

Torjesen, I. (2013). Architect of DSM-5 rejects claims it will lead to labelling of more people as mentally ill. BMJ, 346.

Trump, L., \& Hugo, C. (2006). The barriers preventing effective treatment of South African patients with mental health problems. South Afr Psych Rev, 9(4), 249-260.

Wang, P., Gilman, S., Guardino, M., Christiana, J., Morselli, P., Mickelson, K., et al. (2000). Initiation of and adherence to treatment for mental disorders: examination of patient advocate group members in 11 countries. Med Care, 38(9), 926-936.

WHO. (1992). The ICD-10 classification of mental and behavioural disorders. Clinical descriptions and diagnostic guidelines. Geneva: WHO.

Wisdom, J., \& Green, C. (2004). "Being in a funk": Teens' efforts to understand their depressive experiences. Qual Health Res, 14(9), 1227-1238.

Wong, S., Cheung, A., Lee, A., Cheung, N., Leung, A., Wong, W., et al. (2007). Improving general practitioners' interviewing skills in managing patients with depression and anxiety: a randomized controlled clinical trial. Med Teach, 29(6), e175-e183.

Wykes, T., \& Callard, F. (2010). Diagnosis, diagnosis, diagnosis: towards DSM-5. Journal of Mental Health, 19(4), 301-304. 


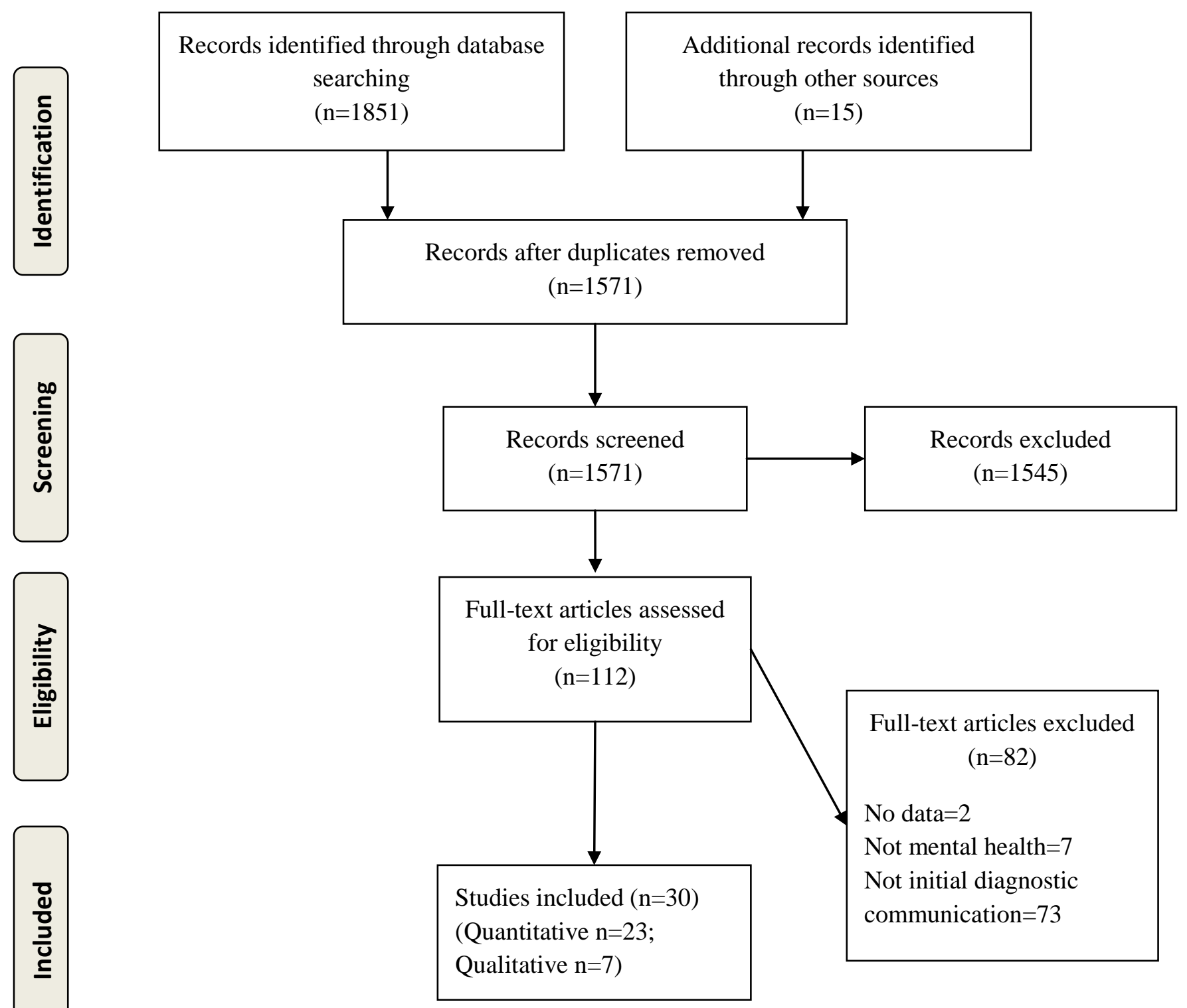

Figure 1. Study Flow 


\section{Table 1. Reviewed Studies}

\begin{tabular}{|c|c|c|c|c|c|}
\hline Reference & $\begin{array}{l}\text { Target Group; Target Mental } \\
\text { Illness }\end{array}$ & $\begin{array}{l}\text { Evidence } \\
\text { Level }\end{array}$ & Country; Location & Study Design & Sample Size; Response-rate \\
\hline [1] (Wong, et al.,2007) & $\begin{array}{l}\text { Clinicians(GPs); Depression \& } \\
\text { Anxiety }\end{array}$ & II & Hong Kong; Outpatient(primary) & $\begin{array}{l}\text { RCT; convenience sample; cross-sectional } \\
\text { recruitment; blinding at assessment. }\end{array}$ & $\begin{array}{l}\text { 32; not-reported(20\% drop- } \\
\text { out rate) }\end{array}$ \\
\hline [2] (Gerrity, et al.,1999) & Clinicians(GPs); Depression & II & USA; Outpatient(primary) & $\begin{array}{l}\text { RCT; convenience sample; cross-sectional } \\
\text { recruitment; blinding at assessment. }\end{array}$ & $\begin{array}{l}\text { 49; not-reported(12.5\% drop- } \\
\text { out rate) }\end{array}$ \\
\hline [3] (Jha, et al.,2001) & $\begin{array}{l}\text { Service-users(Geriatric); } \\
\text { Depression \& Dementia* } \\
\text { * Please note: In depth analysis of dementia }\end{array}$ & is outside the sc & UK; Outpatient(secondary) & $\begin{array}{l}\text { Comparative studies with non-randomized } \\
\text { concurrent controls; convenience sample; } \\
\text { consecutive recruitment. }\end{array}$ & $\begin{array}{l}\text { 53(Dementia), } \\
\text { 47(Depression); 89\% }\end{array}$ \\
\hline [4] (Scardovi, et al.,2003) & $\begin{array}{l}\text { Multifocal(GPs \& service- } \\
\text { users); Mental illness }\end{array}$ & III-3 & Italy; Outpatient(primary) & $\begin{array}{l}\text { Interrupted time series without parallel } \\
\text { control; convenience sample GPs \& service- } \\
\text { users; consecutive recruitment of service- } \\
\text { users; blinding at assessment. }\end{array}$ & $\begin{array}{l}9 \text { (GP), } 515 \text { (service-users); } \\
\text { not-reported ( } 0 \% \text { drop-out } \\
\text { rate) }\end{array}$ \\
\hline [5] (Eisenthal, et al.,1983) & $\begin{array}{l}\text { Multifocal(Service-users \& } \\
\text { Clinicians); Mental illness }\end{array}$ & III-3 & USA; Outpatient(secondary) & $\begin{array}{l}\text { Comparative study without a parallel control } \\
\text { group; consecutive sample; randomization at } \\
\text { recruitment; blinding at assessment. }\end{array}$ & $44 ; 88 \%$ \\
\hline $\begin{array}{l}\text { [6] (Holm-Denoma, et } \\
\text { al.,2008) }\end{array}$ & Service-users; Mental illness & III-3 & USA; Outpatient(secondary) & $\begin{array}{l}\text { Interrupted time series without parallel } \\
\text { control; consecutive convenience sample. }\end{array}$ & $\begin{array}{l}\text { 53; not-reported(21\% drop- } \\
\text { out rate) }\end{array}$ \\
\hline [7] (Luderer \& Bocker,1993) & $\begin{array}{l}\text { Multifocal(Service-users \& } \\
\text { psychiatrists); Mental illness }\end{array}$ & III-3 & Germany; Inpatient & $\begin{array}{l}\text { Comparative study without a parallel control } \\
\text { group; convenience samples; consecutive } \\
\text { recruitment. }\end{array}$ & $\begin{array}{l}230 ; 76.5 \%(23 \% \text { drop-out } \\
\text { rate) }\end{array}$ \\
\hline $\begin{array}{l}{[8] \text { (McNeilly \& }} \\
\text { Wengel,2001) }\end{array}$ & $\begin{array}{l}\text { Clinicians(Medical students); } \\
\text { Mental illness }\end{array}$ & IV-1 & USA; Student training facility & $\begin{array}{l}\text { Pre/post test; convenience sample; } \\
\text { recruitment of cohort. }\end{array}$ & 72; $100 \%(4 \%$ drop-out rate) \\
\hline $\begin{array}{l}\text { [9] (Shergill, et al.,1998) } \\
\text { Part } 2\end{array}$ & $\begin{array}{l}\text { Multifocal(Service-users); } \\
\text { Mental illness }\end{array}$ & IV-1 & UK; Outpatient(secondary) & $\begin{array}{l}\text { Pre/Post test; convenience sample; cross- } \\
\text { sectional recruitment. }\end{array}$ & $23 ; 85 \%$ \\
\hline [10](Cleary, et al.,2010a) & Service-users; Mental illness & IV-2 & Australia; Inpatient & $\begin{array}{l}\text { Descriptive; convenience sample; } \\
\text { consecutive cross-sectional recruitment. }\end{array}$ & $100 ; 71 \%$ \\
\hline [11](Cleary, et al.,2010b) & Clinicians; Mental illness & IV-2 & Australia; Mental health facility & $\begin{array}{l}\text { Descriptive; convenience sample; cross- } \\
\text { sectional recruitment }\end{array}$ & $78 ; 32 \%$ \\
\hline [12](Ganesan, et al.,2011) & $\begin{array}{l}\text { Service-users(Immigrated); } \\
\text { Mental illness }\end{array}$ & IV-2 & Canada; Outpatient(secondary) & $\begin{array}{l}\text { Descriptive; convenience sample; } \\
\text { consecutive recruitment. }\end{array}$ & $173 ; 46 \%$ \\
\hline [13](Thornicroft, et al.,2009) & Service-users; Schizophrenia & IV-2 & Global; Community(various) & $\begin{array}{l}\text { Descriptive; representative convenience } \\
\text { sample; cross-sectional recruitment. }\end{array}$ & 732; not-reported \\
\hline [14](Magliano, et al.,2008) & Service-users; Schizophrenia & IV-2 & Italy; Community(various) & $\begin{array}{l}\text { Descriptive; representative convenience } \\
\text { sample; consecutive recruitment. }\end{array}$ & $250 ; 96 \%$ \\
\hline [15](Trump \& Hugo,2006) & Service-users; Mental illness & IV-2 & South Africa; Community(various) & $\begin{array}{l}\text { Descriptive; representative convenience } \\
\text { sample; cross-sectional recruitment. }\end{array}$ & 331; not-reported \\
\hline [16](Marzanski, et al.,2002) & Service-users; Mental illness & IV-2 & UK; Inpatient & $\begin{array}{l}\text { Descriptive; convenience sample; cross- } \\
\text { sectional recruitment. }\end{array}$ & $35 ; 66 \%$ \\
\hline [17](Seedat, et al.,2002) & Service-users; Mental illness & IV-2 & $\begin{array}{l}\text { South Africa(S.A.) and } \\
\text { International(I); }\end{array}$ & $\begin{array}{l}\text { Descriptive; representative convenience } \\
\text { sample; cross-sectional recruitment }\end{array}$ & $\begin{array}{l}\text { 404(S.A.); 3516(I); } \\
\text { 40\%(S.A.) }\end{array}$ \\
\hline
\end{tabular}




\begin{tabular}{|c|c|c|c|c|c|}
\hline [18](Clafferty, et al.,2001) & $\begin{array}{l}\text { Clinicians(Psychiatrists); } \\
\text { Mental illness }\end{array}$ & IV-2 & $\begin{array}{l}\text { Scotland; Outpatient(secondary; } \\
\text { various) }\end{array}$ & $\begin{array}{l}\text { Descriptive; convenience representative } \\
\text { sample; cross-sectional recruitment. }\end{array}$ & 246; 76\% \\
\hline [19](Wang et al.,2000) & Service-users; Mental illness & IV-2 & International; Community(various) & $\begin{array}{l}\text { Descriptive; convenience representative } \\
\text { sample; cross-sectional recruitment. }\end{array}$ & 3,$516 ; 60 \%$ \\
\hline $\begin{array}{l}\text { [9](Shergill, et al.,1998) } \\
\text { Part } 1\end{array}$ & $\begin{array}{l}\text { Multifocal(Service-users); } \\
\text { Mental illness }\end{array}$ & IV-2 & UK; Inpatient & $\begin{array}{l}\text { Descriptive; convenience sample; cross- } \\
\text { sectional recruitment. }\end{array}$ & $173 ; 72.8 \%$ \\
\hline Part 3 & $\begin{array}{l}\text { Multifocal(Psychiatrists); } \\
\text { Mental illness }\end{array}$ & IV-2 & UK; Inpatient/outpatient(various) & $\begin{array}{l}\text { Descriptive; convenience sample; cross- } \\
\text { sectional recruitment. }\end{array}$ & $24 ; 82 \%$ \\
\hline [20](Mead, et al.,1997) & $\begin{array}{l}\text { Clinicians(Mental health } \\
\text { counselors); Mental illness }\end{array}$ & IV-2 & $\begin{array}{l}\text { USA; Community, } \\
\text { outpatient/inpatient(various) }\end{array}$ & $\begin{array}{l}\text { Descriptive; representative convenience } \\
\text { sample; randomized cross-sectional } \\
\text { recruitment. }\end{array}$ & $380 ; 70.7 \%$ \\
\hline $\begin{array}{l}\text { [21](McDonald-Scott, et } \\
\text { al.,1992) }\end{array}$ & $\begin{array}{l}\text { Clinicians(Psychiatrists); } \\
\text { Mental illness }\end{array}$ & IV-2 & $\begin{array}{l}\text { Japan \& USA; } \\
\text { Community/outpatient(various) }\end{array}$ & $\begin{array}{l}\text { Descriptive; representative convenience } \\
\text { sample; cross-sectional recruitment. }\end{array}$ & $\begin{array}{l}\text { 166(Japan), 112(USA); 51- } \\
\text { 68\% }\end{array}$ \\
\hline [22](Green \& Gantt,1987) & $\begin{array}{l}\text { Clinicians(Psychiatrists); } \\
\text { Mental illness }\end{array}$ & IV-2 & USA; Inpatient/outpatient(various) & $\begin{array}{l}\text { Descriptive; representative convenience } \\
\text { sample; cross-sectional recruitment. }\end{array}$ & $272 ; 90 \%$ \\
\hline [23](Gantt \& Green,1985) & Clinicians; Mental illness & IV-2 & USA; Inpatient/outpatient(various) & $\begin{array}{l}\text { Descriptive; convenience sample; cross- } \\
\text { sectional recruitment. }\end{array}$ & $\begin{array}{l}\text { 132; 88\%(social workers); } \\
\text { other groups not-reported }\end{array}$ \\
\hline [24](Levin, et al.,2011) & $\begin{array}{l}\text { Clinicians(Psychiatrists); } \\
\text { Schizophrenia }\end{array}$ & $\begin{array}{l}\text { Level:5/8 } \\
\text { Strength: } 2 / 4 \\
\text { Relevance: } 3 / 4\end{array}$ & USA; Community(Online) & $\begin{array}{l}\text { Qualitative Thematic analysis; online } \\
\text { convenience sample. }\end{array}$ & not-reported; not-reported \\
\hline [25](Hwang,2008) & $\begin{array}{l}\text { Clinicians(Psychiatrists); } \\
\text { Schizophrenia }\end{array}$ & $\begin{array}{l}\text { Level: } 5 / 8 \\
\text { Strength: } 1 / 4 \\
\text { Relevance:3/4 }\end{array}$ & USA; Outpatient(secondary) & $\begin{array}{l}\text { Qualitative Thematic analysis; convenience } \\
\text { sample. }\end{array}$ & $4 ; 100 \%$ \\
\hline [26](Buston,2002) & $\begin{array}{l}\text { Service-users(Adolescent); } \\
\text { Mental illness }\end{array}$ & $\begin{array}{l}\text { Level: } 5 / 8 \\
\text { Strength: } 2 / 4 \\
\text { Relevance:3/4 }\end{array}$ & UK; Outpatient(secondary) & $\begin{array}{l}\text { Qualitative Grounded Theory; convenience } \\
\text { sample. }\end{array}$ & 32; not-reported \\
\hline [27](Greenwood, et al.,2000) & $\begin{array}{l}\text { Multifocal(Service-users \& } \\
\text { carers); Mental illness }\end{array}$ & $\begin{array}{l}\text { Level: } 6 / 8 \\
\text { Strength: } 2 / 4 \\
\text { Relevance:3/4 }\end{array}$ & UK; Outpatient/community & $\begin{array}{l}\text { Qualitative Grounded Theory; convenience } \\
\text { sample. }\end{array}$ & $\begin{array}{l}\text { 14(Service-users), 10(carers); } \\
70 \%\end{array}$ \\
\hline [28](Gallagher, et al.,2010) & $\begin{array}{l}\text { Service-users; Mental } \\
\text { illness }\end{array}$ & $\begin{array}{l}\text { Level: } 5 / 8 \\
\text { Strength: } 2 / 4 \\
\text { Relevance:3/4 }\end{array}$ & UK; Inpatient/Outpatient & $\begin{array}{l}\text { Qualitative Grounded Theory; convenience } \\
\text { sample. }\end{array}$ & 10; not-reported \\
\hline [29](Wisdom \& Green,2004) & $\begin{array}{l}\text { Service-users(Adolescent); } \\
\text { Depression }\end{array}$ & $\begin{array}{l}\text { Level: } 6 / 8 \\
\text { Strength: } 2 / 4 \\
\text { Relevance: } 2 / 4 \\
\end{array}$ & USA; Community & $\begin{array}{l}\text { Qualitative Grounded Theory; convenience } \\
\text { sample. }\end{array}$ & 22; not-reported \\
\hline [30](Lewis,1995) & Service-users; Depression & $\begin{array}{l}\text { Level: } 7 / 8 \\
\text { Strength: } 3 / 4 \\
\text { Relevance:3/4 }\end{array}$ & UK; Outpatient/Community & $\begin{array}{l}\text { Qualitative Grounded Theory; convenience } \\
\text { sample. }\end{array}$ & 48; not-reported \\
\hline
\end{tabular}




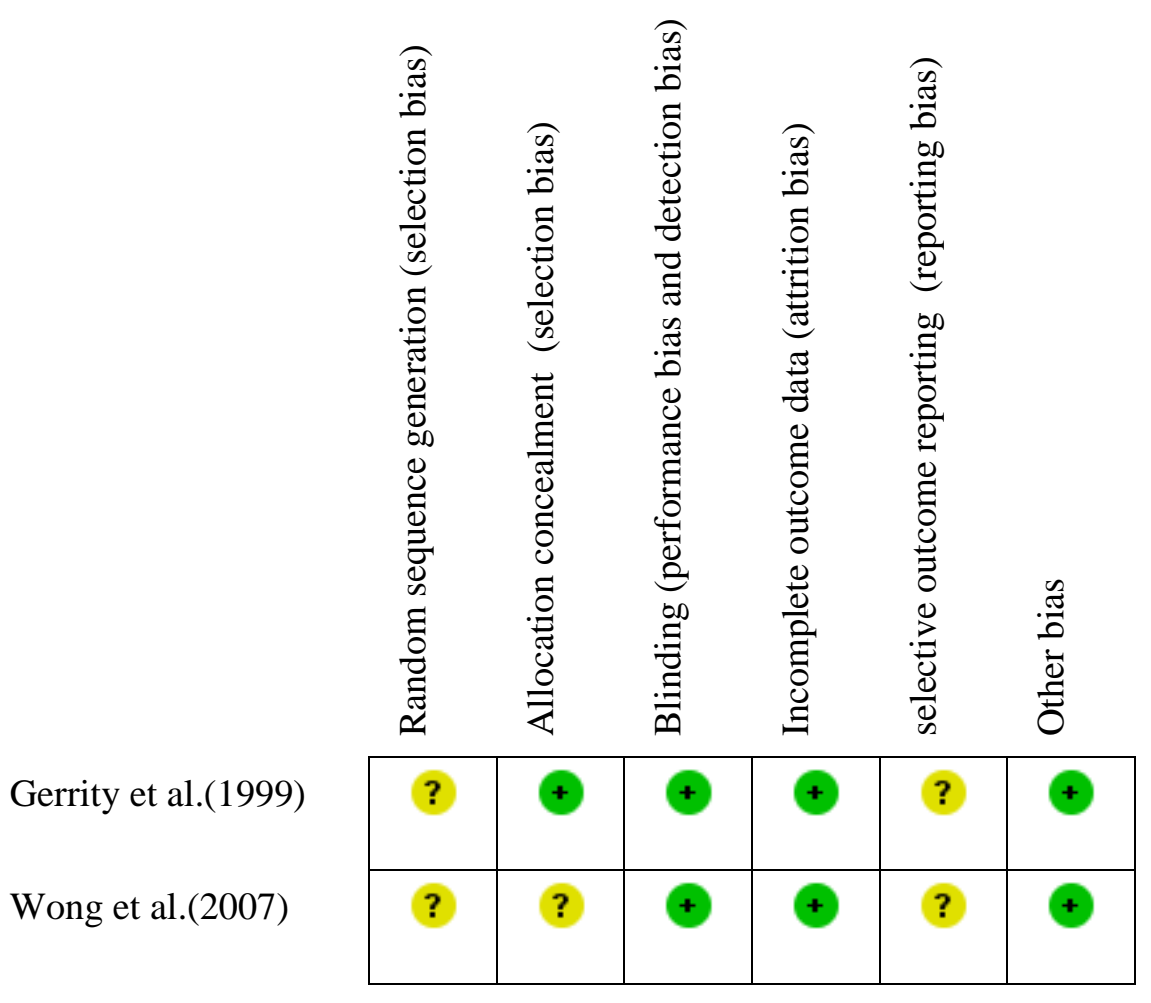

Figure 2. Risk of Bias Summary for Level II RCTs 


\begin{tabular}{ll}
\hline Item & References \\
\hline Facilitation & \\
Preferred Psychiatrist/Doctor available & {$[9,10,16]$} \\
Service-user involvement & {$[10]$} \\
Family involvement & {$[10]$} \\
Sufficient time for conversation & {$[10]$} \\
Timely information provided & {$[10]$} \\
Ensuring privacy & {$[10]$} \\
Staff honesty & {$[10]$} \\
Empathy & {$[10]$} \\
Hope & {$[10]$} \\
Respond to feelings/emotions & {$[10]$} \\
Listening \& Supporting & {$[10]$} \\
Staff tact & {$[10]$} \\
& \\
Content & \\
Explore the service-user's understanding of the situation & {$[10]$} \\
Medication side-effects & {$[10]$} \\
Support groups & {$[10]$} \\
Written information & {$[3,10]$} \\
Useful websites & {$[10]$} \\
Community resources & {$[10]$} \\
Treatment option information & {$[10,16]$} \\
Medication benefits explained & {$[10]$} \\
Illness specific information & {$[10,16]$} \\
Typical symptoms expected & {$[10]$} \\
Etiology & {$[16]$} \\
Priagnosis & {$[10,14,16]$} \\
Explain what to expect & {$[10,16]$} \\
Accurate/reliable information & {$[10]$} \\
Discuss fears/concerns & {$[10]$} \\
Check if more information is wanted & {$[10]$} \\
Check understanding & {$[10]$} \\
Ensure questions answered & {$[10]$} \\
& \\
\hline
\end{tabular}


Table 3. Impact of Interventions: clinician skills, service-user satisfaction and mood

\begin{tabular}{|c|c|c|c|c|}
\hline Item & $\begin{array}{l}\text { Service- } \\
\text { user } \\
\text { Satisfaction }\end{array}$ & $\begin{array}{l}\text { Service- } \\
\text { user } \\
\text { Mood (+ive) }\end{array}$ & Clinician Skills & Reference \\
\hline \multicolumn{5}{|c|}{ ( } \\
\hline Clinician awareness of counter-transference & & & $\mathrm{S} \uparrow$ & [8] \\
\hline Clinician awareness of boundaries & & & $\mathrm{S} \uparrow$ & [8] \\
\hline Clinician awareness of diagnostic communication strategies & & & $\mathrm{S} \uparrow$ & [8] \\
\hline Initiate discussion & & & NS个 & [1] \\
\hline Structure consultation & & & NS个 & [1] \\
\hline Understand patient’s perspective & & & NS个 & [1] \\
\hline Active listening \& facilitating service-users response & & & $\mathrm{S} \uparrow$ & [1] \\
\hline Seek service-users views & $\mathrm{S}$ & & NS个 & {$[4,5]$} \\
\hline Assess service-user satisfaction & & & NS个 & [2] \\
\hline Rapport & & & NS个 & [2] \\
\hline Non-verbal communication skills & & & NS个 & [1] \\
\hline Clinician use of authority & NS & & & [5] \\
\hline Gives supportive feedback & & & $\mathrm{S} \uparrow$ & [3] \\
\hline Manner in which plan is raised by clinician & NS & & & [5] \\
\hline Scheduled follow up & & & NS个 & {$[1,2,4]$} \\
\hline Participatory decision making consensus & $\mathrm{S}$ & & $\mathrm{S} \uparrow$ & {$[2,5]$} \\
\hline Establish realistic goals & & & $\mathrm{S} \uparrow$ & [4] \\
\hline Promote problem solving & & & NS个 & [4] \\
\hline Closure & & & NS个 & {$[1]$} \\
\hline \multicolumn{5}{|l|}{ Content } \\
\hline Physical treatment information & & & NS个 & [4] \\
\hline Psychological treatment information/explanation & $\mathrm{S}$ & & $\mathrm{S} \uparrow$ & {$[4,5]$} \\
\hline Advice on mental health management & & & $\mathrm{S} \uparrow$ & [4] \\
\hline Relate information to referral reason & & & $\mathrm{S} \uparrow$ & [4] \\
\hline Examine specific examples & & & $\mathrm{S} \uparrow$ & [4] \\
\hline Discussed possibility of mental illness & & & NS个 & {$[1,2]$} \\
\hline Provide Diagnostic Feedback & & $\mathrm{S} \uparrow$ & & {$[6]$} \\
\hline Prescribe Medication & & & NS个 & [1] \\
\hline Discuss Medication & & & $\mathrm{S} \uparrow$ & [4] \\
\hline Relate diagnosis to problems & $\mathrm{S}$ & & $\mathrm{S} \uparrow$ & {$[4,5]$} \\
\hline Clear explanation and planning & $\mathrm{S}$ & & NS个 & {$[1,5]$} \\
\hline Negotiating mutual plan & & & $\mathrm{S} \uparrow$ & {$[1,4]$} \\
\hline Clear of rationale behind treatment plan & $\mathrm{S}$ & & & [5] \\
\hline Match of treatment plan to the service-users initial request & NS & & & [5] \\
\hline
\end{tabular}

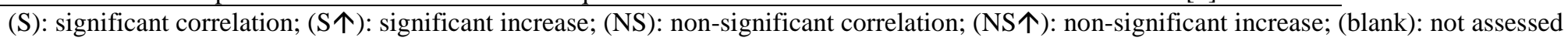


Table 4. Various models for communicating a MHD

\section{SPIKES Protocol}

Setting up the interview.

\section{Additional recommendations for communication diagnostic news}

[24] Prepare for meeting.

[25] Clinicians assess own feelings and motivations towards disclosure; ensure the right timing by establishing a relationship and ensuring symptoms have stabilized; include family in process; use status of authority figures to promote service-user participation in process; coordinate mental health services.

\section{Assessing the patient's Perception of their [24] Reviewing service-users and carers understanding of schizophrenia. \\ medical circumstances.}

Obtaining the patient's Invitation to receive [24] Negotiating agenda collaboratively, maximizing care engagement.

the information.
Giving the requisite Knowledge and information.
[24] Communicate diagnosis; discuss prognosis, treatment and meaning of "schizophrenia"; provide education and promote a recovery framework.

[25] Demystify treatment process; provide balanced psycho-education with mind body and spirit; promote independence and self management; provide psycho-education hand-outs.

[6] Introduce agenda; reflect main symptoms the service-user reported; disclose diagnosis; provide information; give assurance that the clinician has knowledge of treatments; advise to guard against misinformation; answer questions.

\begin{tabular}{ll}
\hline $\begin{array}{l}\text { Responding Empathically to the patient's } \\
\text { Emotions as a consequence of the news. }\end{array}$ & $\begin{array}{l}\text { [24] Providing empathy; reduce stigma. } \\
\text { [25] Normalize; decrease stigma. }\end{array}$ \\
$\begin{array}{l}\text { Summarize the treatment processes and } \\
\text { next few Steps. }\end{array}$ & [24] Summarizing session, plan follow-up. \\
\end{tabular}

next few Steps.

[25] Follow-up. 